\title{
Argumentación científica escolar y su contribución al aprendizaje del tema «salud y enfermedad»
}

\author{
Andrea Revel Chion (iD, Carlos A. Díaz Guevara \\ Instituto CeFIEC. Facultad de Ciencias Exactas y Naturales. Universidad de Buenos Aires. Ciudad \\ Autónoma de Buenos_Aires.Argentina.andrearevelchion@gmail.com, carlosalberto.diazguevara@yahoo.es \\ Agustín Adúriz-Bravo iD \\ CONICET-Instituto CeFIEC. Facultad de Ciencias Exactas y Naturales. Universidad de Buenos Aires. \\ Ciudad Autónoma de Buenos Aires. Argentina. aaduriz̧bravo@refiec.fcen.uba.ar
}

[Recibido: 1 septiembre 2020. Revisado: 8 noviembre 2020. Aceptado: 27 febrero 2021]

\begin{abstract}
Resumen: El presente artículo pretende contribuir a la discusión sobre los alcances que tiene la argumentación científica escolar en el aprendizaje de las ciencias experimentales y particularmente de los conceptos de salud y enfermedad. En primer lugar, se articulan diversos aportes teóricos sobre la argumentación y se precisa el posicionamiento ilocutivo de este trabajo. Luego se discute una secuencia didáctica, puesta en aula por una de los autores, que persiguió el objetivo de que estudiantes de enseñanza secundaria argumentaran en torno a la enfermedad llamada porfiria eritropoyética congénita apuntando a audiencias específicas. En la secuencia didáctica se acompañó al estudiantado en la producción de sus argumentos y se apoyó la inclusión de cuatro componentes específicas en sus textos: teórica, lógica, pragmática y retórica. Aquí se analizan las producciones escritas, derivadas de una tarea de retextualización, de un grupo de cinco estudiantes seleccionados intencionadamente, con el fin de identificar posibles aportes del proceso de argumentación al aprendizaje de los conceptos de salud en juego.
\end{abstract}

Palabras clave: Argumentación científica escolar; Salud y enfermedad; Modelo ilocutivo; Retextualización.

School scientific argumentation and its contribution to learning the topic «health and disease»

\begin{abstract}
This article intends to contribute to the discussion around the scope of school scientific argumentation in the learning of science and in particular of the concepts of health and disease. In the first place, various theoretical contributions on argumentation are presented, and the illocutionary positioning of this study is specified. Then, a didactical sequence is discussed; the sequence was implemented in the classroom by one of the authors, and had as aim that secondary-school students argued about the disease called congenital erythropoietic porphyria targeting specific audiences. In the sequence, students were accompanied in the production of their arguments and the inclusion of four specific components in their texts was supported: theoretical, logical, pragmatic and rhetorical. Here, the written productions, derived from a task of re-textualisation, of a group of five intentionally selected students are analysed in order to identify possible contributions of the argumentation process to the learning of the concepts of health that were being discussed.
\end{abstract}

Keywords: School scientific argumentation; Health and disease; Illocutionary model; Re-textualisation.

Para citar este artículo: Revel Chion A., Díaz Guevara C.A. y Adúriz-Bravo A. (2021). Argumentación científica escolar y su contribución al aprendizaje del tema «salud y enfermedad» Revista Eureka sobre Enseñanza y Divulgación de las Ciencias 18(3), 3101.doi: 10.25267/Rev_Eureka_ensen_divulg_cienc.2021.v18.i3.3101

\section{Introducción}

$\mathrm{Al}$ interior de las comunidades académicas de didactas y pedagogos, y muy especialmente entre quienes investigan en la didáctica de las ciencias experimentales, se advierte un fuerte consenso en torno de la importancia del lenguaje en los procesos de aprendizaje (Revel Chion y Adúriz-Bravo 2014). Dentro de los diferentes géneros discursivos, la argumentación es reconocida como particular candidata para impactar muy positivamente en los aprendizajes de los contenidos científicos escolares, que se robustecen conforme se aprende a argumentar 
sobre ellos (Leitão 2007). Al poner en marcha la argumentación como competencia, el colectivo docente accede a identificar, en las producciones argumentativas de sus estudiantes, la calidad de tales aprendizajes mucho más cabalmente que con otros géneros discursivos. Así, poner énfasis en la enseñanza de la competencia argumentativa a partir de su incorporación formal en el currículo escolar resulta central para alcanzar una alfabetización científica de calidad para todos y todas (Ibacache y Merino 2021).

Acordamos con una de las tesis centrales del trabajo de Özdem y colaboradores (2017), en el sentido de que la efectiva implementación de la argumentación en las aulas de ciencias de los distintos niveles educativos requiere que previamente ella sea incluida en los currículos de los centros de formación del profesorado, de manera tal que quienes serán docentes salgan habilitados para diseñar, implementar y evaluar actividades destinadas al dominio de la competencia argumentativa. Se perciben, sin embargo, algunas disonancias a este respecto, porque los acuerdos y consensos que se visualizan muy nítidamente en la comunidad de didactas se desdibujan cuando se focaliza la mirada en lo que efectivamente sucede tanto en las aulas de formación docente como en la educación científica en general. Hay varias hipótesis que podrían dar cuenta de la ausencia de cristalización efectiva de experiencias de enseñanza de la argumentación, fruto de las prescripciones derivadas de la investigación didáctica: desde el férreo apego a los contenidos declarativos de las disciplinas, que reclaman para sí todo el tiempo de clase, hasta la ausencia de una enseñanza sostenida y reflexiva de la argumentación en la profesionalización docente.

Tenemos entonces un escenario en el que un ingente número de trabajos que señalan el impacto positivo del dominio de la competencia argumentativa en el aprendizaje de los contenidos científicos no logra instalar su abordaje sostenido en las aulas de los diferentes niveles educativos. Con base en esta situación, proponemos aquí una nueva reflexión sobre la argumentación científica escolar que se apoya en un modelo didáctico que, a nuestro entender, es a la vez potente y accesible para que el profesorado lo implemente con sus estudiantes. Este modelo «ilocutivo» hace pie en el reconocimiento de la relevancia que tiene el desarrollo de habilidades metacognitivas para contribuir a la autorregulación del estudiantado, expectativa de logro demandada a nivel curricular y poco estimulada en las clases de ciencias.

Las preguntas de investigación que guían este trabajo atañen al aprendizaje de la argumentación científica y su interacción con los modelos biológicos escolares sobre salud en estudiantes de enseñanza secundaria. Operando un recorte sobre datos provenientes de un estudio cualitativo exploratorio de dos aulas, analizamos producciones escritas de cinco estudiantes de diferente rendimiento seleccionados intencionadamente. Tales producciones son el resultado de una tarea de retextualización de la explicación científica sobre la enfermedad llamada «mal de Günther»; pretendemos identificar en ellas posibles aportes del proceso de argumentación al aprendizaje de los conceptos sobre salud en juego.

\section{Marco teórico}

\section{Diferentes perspectivas sobre la argumentación}

El amplio alcance que se da al término «argumentación» desde las ciencias del lenguaje y otras disciplinas (Archila 2013, 2015) permite que se lo relacione con ideas tales como: vehículo y soporte para establecer criterios de autoridad epistémica, medio de persuasión por antonomasia, forma privilegiada de zanjar disputas y controversias, explicación razonada y «desplegada» de conceptos científicos y modelo de justificación de afirmaciones, entre otras. Ello nos exige ser cuidadosos y precisar cuáles son los márgenes dentro de los que vamos a definir la argumentación en el marco didáctico. En virtud de esta amplitud, expondremos algunas perspectivas para luego presentar aquella a la que adscribimos, respecto de la cual 
haremos una presentación teórica y una elucidación de su puesta en acción como estrategia de enseñanza y de evaluación.

A finales de los años 50, Perelman y Olbrechts-Tyteca publican el Tratado de argumentación: La nueva retórica, y será precisamente aquí cuando aparezca en la escena argumentativa la figura del «receptor». La propuesta de estos autores enfatiza el arte de la persuasión y distingue qué supone persuadir y qué convencer (Perelman y Olbrechts-Tyteca 1970); en este sentido, de acuerdo con su interpretación, se persuade en el plano de los sentimientos (que es individual) y se convence a la razón (a nivel colectivo).

Perelman (1979) propone una idea sugerente: la de «fuerza argumentativa», que puede conceptualizarse como la intensidad con la que el receptor de un argumento adhiere a él en función de la relevancia que le concede. A su vez, reconoce la solidez de un argumento en tanto puede cumplir la «regla de justicia»-que demanda solvencia en la disciplina en la que se inserta el argumento. Tal regla dictamina acerca de la calidad argumentativa en función de la posibilidad de convencer de aquello que un argumento defendió en una situación análoga anterior.

Por su parte, el filósofo inglés Stephen Toulmin, cuyas propuestas fueron extensamente consideradas para la enseñanza de la argumentación científica en los diferentes niveles educativos (Özdem et al. 2017, Ibacache y Merino 2021), afirma que los argumentos de tipo «sustancial» ofrecen evidencias empíricas y de otras clases para apoyar la conclusión, y que se despliegan en el contexto social, en la interacción con los otros. El modelo propuesto por Toulmin (1958) pretende dar cuenta de las argumentaciones en el marco de discursos sociales, conversaciones entre sujetos, medios de comunicación gráficos y audiovisuales, entrevistas e interacciones en clase, entre otros contextos situacionales.

El esquema de Toulmin opera a partir de unos datos o evidencias, sobre los que se formula una conclusión. Una «garantía» o justificación, que vincula los datos con la conclusión, y un respaldo ofrecen el fundamento teórico, práctico o experimental para el pasaje de datos a conclusiones. Los cualificadores modales, tales como «ciertamente» o «probablemente», señalan el modo de interpretar la validez de la conclusión. Finalmente, en el modelo se considera la pertinencia de ciertas objeciones o reservas a dicha conclusión.

En la Europa continental, van Eemeren y Grootendorst (1984) desarrollan la teoría pragmadialéctica de la argumentación. Pretenden contar con un dispositivo que analice y evalúe los argumentos en su contexto, entendiéndolos como una práctica natural del lenguaje. El enfoque pragma-dialéctico focaliza el interés en la producción de argumentos con potencia persuasiva. De acuerdo con los autores, la argumentación es un medio para resolver diferencias de opinión; se asume así que se deberá enfatizar la importancia de considerar las interacciones emisor-receptor. Un problema teórico básico, pero no por ello poco complejo, en la teoría de la argumentación es, precisamente, discernir con propiedad el papel que juega el peso de la prueba en los razonamientos desplegados en diálogos controversiales. En otro texto, van Eemeren, Grootendorst y Snoeck-Henkemans (2007) postulan que ese concepto de «peso de la prueba» es esencial en el análisis de las discusiones y debates: se requiere distinguir quién posee el peso de la evidencia en una discusión para observar las partes involucradas y distribuir las posiciones de protagonista y antagonista. Según la teoría pragma-dialéctica, en una discusión crítica el peso de la evidencia siempre corre por cuenta de quien ha sido desafiado a dar razones de sus argumentos.

Douglas Walton, filósofo canadiense interesado especialmente en las prácticas argumentativas en el ámbito legal, modeló, a finales de la década de los ochenta, sus propuestas relativas a la argumentación en el contexto de investigaciones e innovaciones de enseñanza con estudiantes 
de leyes. La pretensión inicial fue que sus ideas teóricas sirvieran como insumo para el análisis crítico de los «casos» que el estudiantado tuviera que abordar argumentativamente. Walton (1989) asume un enfoque dialógico de la argumentación: una concepción conversacional en la que la evaluación de la pertinencia de los argumentos debe considerar el razonamiento en contexto y la interacción entre emisor y receptor. Según su concepción, todo argumento se basa en un desacuerdo sobre un hecho que podría ser considerado verdadero por uno de los sujetos que sostienen el diálogo. Él afirma que las personas argumentan cuando existen discrepancias entre ellas, lo que las obliga a aportar razones que apoyen sus respectivos puntos de vista, con el fin de convencer al otro.

En variados ámbitos profesionales y disciplinares, la práctica argumentativa exige que se expongan razones para defender un determinado posicionamiento; la explicitación de las relaciones entre posicionamiento y razones conforma el argumento. De este hecho se desprende que la evaluación de un argumento depende de la naturaleza, encuadre y apoyos del punto de vista a defender. El enfoque de Walton evalúa la pertinencia de los argumentos a la luz de la robustez de los razonamientos implicados en ellos y, al mismo tiempo, del contexto del diálogo en el que se desarrollan. Será precisamente este aspecto el que motive a algunos investigadores interesados en la argumentación en la enseñanza de las ciencias (Rescher 1976, Duschl y Gitomer 1997, Duschl 2008) a reconocer este modelo como particularmente adecuado para guiar las secuencias argumentativas que se suscitan en los diálogos grupales en clase.

Deanna Kuhn propuso a fines del siglo XX conceptualizar el aprendizaje de las ciencias como argumentación, en contraste con la concepción del aprendizaje exclusivamente como «exploración». Ella considera que argumentar es un proceso cognitivo complejo que debe ser objeto de enseñanza, al tiempo que afirma que es prometedora aquella educación en ciencias que estimula «modos» de pensar. En este sentido, si el desarrollo de formas científicas de pensar es la meta fundamental de la enseñanza de las ciencias, es esencial echar luz sobre qué significa pensar científicamente y cómo esto involucra fuertemente al colectivo docente (Kuhn 1993). La investigadora señala que es factible usar los argumentos como una suerte de ventana a través de la cual es posible mirar qué y cómo piensan los estudiantes, ya que el diálogo argumentativo sería la exteriorización del «razonamiento argumentativo».

En sintonía con las concepciones de argumentación que intentan «desmarcarse» de una excesiva ligazón con la lógica formal, Christian Plantin (2012) alerta acerca de la necesidad de contemplar que quien argumenta es un sujeto atravesado por pasiones de diferente tipo, que gestiona con dispar solvencia. Tales pasiones también alcanzan al receptor del argumento. El modelo dialogal de Plantin asume que la argumentación es una actividad costosa tanto desde el punto de vista cognitivo como desde el aspecto interpersonal, porque los interlocutores deben desarrollar ideas, buscar razones, aportar argumentos, justificar sus reservas a las razones recibidas y tratar de refutar las buenas razones que sustentaron la proposición original (Plantin 2012). Este modelo dialogal, por tanto, reconoce la situación argumentativa como el desarrollo y la confrontación de puntos de vista contradictorios frente a una pregunta.

\section{La argumentación científica escolar: Un modelo de argumentación para las clases de ciencias}

La concepción de «argumentación científica escolar» que se enmarca en el llamado modelo cognitivo de ciencia escolar (Izquierdo et al. 1999, Izquierdo-Aymerich y Adúriz-Bravo 2003) atiende a que la ciencia que se desarrolla en el ámbito escolar expone continuidades y rupturas con su contraparte erudita. En este sentido, la ciencia que se despliega en las aulas persigue que los estudiantes piensen con modelos teóricos y que tales modelos sean comunicados adecuadamente, atendiendo a que el lenguaje no solo configura la comunicación, sino que es la 
vía privilegiada para la comprensión de los conceptos científicos. Dentro de este encuadre teórico, Adúriz-Bravo (2012) asume que la argumentación científica escolar es una práctica epistémica, un pilar fundamental de la naturaleza de la ciencia, y un modo de apropiación y uso de los modelos teóricos con los cuales se da sentido al mundo.

Esta concepción de ciencia escolar demanda un modelo de explicación y argumentación que sea coherente con sus principios y particularidades. Un modelo ilocutivo se ajusta a dichas demandas, en función de la importancia que concede al mismo tiempo a la propia estructura de la explicación y a su resultado: el impacto que la argumentación tiene en el receptor. El modelo de explicación pragmático-ilocutivo, surgido en los años 50 , propone considerar a los usuarios del lenguaje y, fundamentalmente, los contextos de uso. Se asume que una comunicación es ilocutiva en tanto en ella se expone un contenido susceptible de ser comprendido por el receptor, pero que además genera un efecto en él.

Como se dijo, en este modelo didáctico, la ciencia escolar y la erudita comparten el objetivo de querer comprender el mundo y comunicar las ideas teóricas respecto del mismo en un modo apropiado; en ese sentido, el lenguaje se convierte en una cuestión central en el aprendizaje y la enseñanza de las ciencias (Izquierdo-Aymerich y Adúriz-Bravo 2003). Coherente con ello, Adúriz-Bravo $(2008,2012)$ define la argumentación científica escolar como la producción de un texto en el cual se explica con base en «evidencias». La competencia argumentativa -incluida entre las competencias cognitivo-lingǘsticas- satisface dos requerimientos: es central para llevar adelante la actividad científica y, al mismo tiempo, su dominio posibilita vislumbrar la naturaleza profunda de dicha actividad, razón por la cual es insoslayable en una educación científica de calidad.

Un elemento central del modelo de argumentación científica escolar que utilizamos en nuestra investigación son las cuatro componentes que Adúriz-Bravo (2012), con base en insumos teóricos de la filosofía de la ciencia, reconoce en un argumento «bien formado»:

1. La componente retórica, que alude a la voluntad de convencer al interlocutor y de cambiar el estatus que un determinado conocimiento tiene para él.

2. La componente pragmática, que deja de manifiesto que toda argumentación se produce en un contexto al cual se ajusta y adecua, y del cual toma sentido.

3. La componente teórica, que se refiere al requerimiento de la existencia de un modelo teórico que sirve de referencia al proceso explicativo.

4. La componente lógica, relacionada con la estructura sintáctica compleja del texto producido.

Estas componentes se pueden aplicar a la enseñanza de la argumentación científica escolar con tres objetivos convergentes: 1. guiar el diseño y puesta en marcha de actividades para enseñar al estudiantado y al profesorado a argumentar; 2 . servir de instrumento para comunicar a estas poblaciones blanco qué características son las propias de una buena argumentación; y 3. dar orientaciones para analizar y (auto)evaluar los textos producidos.

En un artículo reciente, Jonathan Osborne y Alexis Patterson (2011) esbozan la pregunta acerca de si es necesario realizar una distinción entre los términos de «argumentación»y «explicación» científicas; proponen una respuesta afirmativa: las explicaciones persiguen el objetivo de responder al interrogante ipor qué?, mientras que las argumentaciones buscan persuadir al receptor acerca de la validez de una conclusión. La diferencia entre ambas es su función epistémica: mientras que las explicaciones buscan aportar mayor comprensión de un fenómeno, las argumentaciones intentan justificar afirmaciones. 
Pero en los contextos de enseñanza de las ciencias de los niveles primario y secundario ya no resulta tan sencillo identificar esas diferencias porque, desde la perspectiva ilocutiva, el objetivo perseguido con una explicación científica escolar es persuadir a los receptores (las y los estudiantes) del valor epistémico de las ideas presentadas. Se trata de un objetivo didáctico que hace que se solapen los modos de explicar y argumentar. En estos contextos, nos parece prudente asumir que la argumentación científica escolar supone la producción de un texto explicativo que persigue el objetivo de persuadir al receptor de la potencia de su contenido y de la conveniencia de que él/ella modifique el estatus del conocimiento con que contaba.

Respecto de esta explicación-argumentación, Richard Duschl (1997) la ubica en el «vértice» de la pirámide científica, ya que para él representa la habilidad científica más elaborada y compleja, que pone los modelos al servicio de dar sentido al mundo. Cuando se elabora una explicación científica de algún fenómeno se recurre a lenguajes del contexto científico que, entre otras dimensiones, describen o definen los modelos teóricos que se aceptan en un momento histórico determinado (Izquierdo-Aymerich y Adúriz-Bravo 2003).

Finalmente, nos resulta necesario resaltar también que nuestra concepción de argumentación como una «explicación desplegada que convence» parece potente para una enseñanza sociocientifica del tema curricular de «salud y enfermedad». Nuestra propuesta se suma así a algunos trabajos anteriores donde se explora este tema desde la perspectiva argumentativa, como el de Ageitos y colaboradores (2016) y el de Maguregi y colaboradores (2017). El primero presenta una secuencia didáctica para estudiantes de nivel secundario centrada en el aprendizaje de enfermedades genéticas y pretende fomentar las prácticas científicas de argumentar y modelizar con vistas a promover pensamiento crítico, procesos de razonamiento y toma de decisiones. El segundo valora la construcción de un modelo científico escolar de sistema inmunológico en futuro profesorado de nivel primario a través del examen detallado de sus producciones escritas y discusiones orales de carácter argumentativo en torno al concepto de vacuna.

\section{¿Cómo se ha propuesto enseñar a argumentar?}

La introducción de la argumentación en las aulas de ciencias experimentales ha sido abordada por diferentes grupos de investigación con sus respectivas improntas. El pionero proyecto RODA (Razonamiento, Discurso, Argumentación) de la Universidad de Santiago de Compostela adoptó una perspectiva en la que se considera que la enseñanza de los elementos que conforman una argumentación no representa la tarea más importante, ya que esta competencia, al igual que muchas otras, se aprende conforme se practica. Por ello, el proyecto propone la inmersión de los estudiantes en experiencias concretas que los estimulen a producir argumentos; es en este tipo de experiencias en las que se aprenderían tanto las reglas de una argumentación como los contenidos científicos sobre los cuales se argumenta.

Por su parte, el proyecto IDEAS (Ideas, Evidence and Argument in Science Education), conducido en 2004 por Jonathan Osborne, Sibel Erduran y Shirley Simon en el King's College de Londres, proponía una etapa inicial de enseñanza explícita de la argumentación y los elementos de un argumento en versión toulminiana. En etapas posteriores se llevaban a cabo actividades de producción de argumentos, tales como evaluar el trabajo de un compañero o compañera y tomar decisiones acerca de qué teorías explican mejor un determinado fenómeno.

El proyecto IQWST (Investigating and Questioning our World through Science and Technology), dirigido por Brian Reiser en la Northwestern University de Estados Unidos en 2007, propuso tanto la enseñanza explícita de la argumentación como la aportación de criterios y estándares para evaluar conclusiones, pruebas y justificaciones. Las prácticas de argumentación se 
desarrollaban a través de actividades con el apoyo de software diseñado de manera tal que los estudiantes pudieran seleccionar pruebas en situaciones diferentes.

El programa WAC (Writing Across the Curriculum), encabezado por Charles Bazerman de la Universidad de California (Estados Unidos) y actualmente vigente, enfatiza la importancia de enseñar a escribir en el seno de las disciplinas. El interés se centra en identificar y comprender en qué consiste la escritura académica y cómo varía en los diferentes dominios del saber; el foco está puesto en enseñar al estudiantado las particularidades que exigen los textos en cada disciplina, entre ellos, los argumentativos.

Más allá de sus particularidades, los proyectos que aquí hemos reseñado coinciden en afirmar que el clima y la cultura de la clase (por ejemplo, los modos en los que el profesorado gestiona el diálogo y las interacciones de ideas entre sus estudiantes) son fundamentales, y se constituyen en la condición básica para favorecer el aprendizaje de la argumentación. Tuvimos esto muy en cuenta para el diseño de nuestra secuencia didáctica.

\section{Metodología}

El desarrollo de la propuesta de intervención que produjo los datos que aquí se analizan tuvo lugar en dos cursos correspondientes al último año de escuela secundaria (estudiantes de 17-18 años) en la ciudad de Buenos Aires, Argentina, en el marco de la asignatura Educación para la Salud. La muestra que participó en cada una de las actividades de nuestra secuencia didáctica de argumentación estuvo constituida por un total de 51 estudiantes. La primera autora de este trabajo, en el doble rol de docente e investigadora, participó de la construcción de la secuencia, su puesta en marcha, la evaluación de la misma y el análisis de los resultados.

Los dos cursos en los que intervinimos trabajaban por segundo año consecutivo con la docente-investigadora, que siempre otorga en sus clases un rol muy destacado a la escritura científica. Así, las y los estudiantes de nuestra investigación estaban habituados a utilizar diferentes géneros discursivos y a emplear figuras retóricas como las analogías; durante el trabajo en distintas actividades didácticas, fueron invitados a reconocer tales figuras en diferentes textos y a «desocultar» su significado biológico.

La secuencia didáctica completa con la que se trabajó (Tabla 1) apunta al aprendizaje de la escritura en biología e incluye distintos tipos de actividades, de acuerdo con la tipología propuesta por Neus Sanmartí (2005). La secuencia tiene un fuerte cariz argumentativo, en tanto reconoce como de vital importancia aprender a comunicar y sustentar ideas de ciencias experimentales estructuradas con base en un modelo científico escolar.

En la implementación de la secuencia completa, las cuatro componentes de la argumentación guiaron la construcción de unas «bases de orientación» que oficiaron de instrumento regulador de las producciones pedidas al estudiantado, atendiendo al logro de capacidades metacognitivas y autorregulatorias. Las y los estudiantes participantes elaboraron argumentaciones dirigidas a distintos tipos de receptores, en coherencia con el modelo ilocutivo que se asumió para este trabajo. Se introdujeron en la secuencia varias instancias de evaluación de las producciones bajo la estructura de hétero-, co- y autoevaluaciones, en las que se potenció el empleo de las bases en ejercicios de nivel metacognitivo. 
Tabla 1. Categorización de las actividades de la secuencia didáctica completa (tomada de Revel Chion 2012: 101). Se subraya la actividad de aplicación que se discute en este trabajo.

\begin{tabular}{|c|c|c|}
\hline Actividad & Tipo & Objetivos \\
\hline $\begin{array}{l}\text { Pretest: El caso de la gripe } \\
\text { porcina }\end{array}$ & $\begin{array}{l}\text { Actividad de } \\
\text { iniciación y } \\
\text { exploración }\end{array}$ & $\begin{array}{l}\text { Relevar las características que el estudiantado consideraba } \\
\text { debían ser incluidas en un texto de tipo explicativo. Inferir } \\
\text { concepciones de salud y enfermedad subyacentes. }\end{array}$ \\
\hline ¿Qué es la salud? & $\begin{array}{l}\text { Actividad de } \\
\text { iniciación y } \\
\text { exploración }\end{array}$ & $\begin{array}{l}\text { Identificar la concepción del estudiantado en relación con la } \\
\text { salud. }\end{array}$ \\
\hline \multicolumn{3}{|c|}{ Presentación de la evolución del concepto de salud y ambiente } \\
\hline $\begin{array}{l}\text { Por qué reaparecen las } \\
\text { epidemias }\end{array}$ & $\begin{array}{l}\text { Actividad de } \\
\text { iniciación y } \\
\text { exploración }\end{array}$ & $\begin{array}{l}\text { Identificar las características de los textos explicativos } \\
\text { producidos por el estudiantado. }\end{array}$ \\
\hline \multicolumn{3}{|c|}{ Narrativa «Peste negra medieval» } \\
\hline Qué dijo la profesora & $\begin{array}{l}\text { Actividad de } \\
\text { evolución de los } \\
\text { modelos }\end{array}$ & Identificar la adecuación del texto al receptor. \\
\hline Explicación a la madre & $\begin{array}{l}\text { Actividad de } \\
\text { evolución de los } \\
\text { modelos }\end{array}$ & $\begin{array}{l}\text { Reconocer hasta qué punto el estudiantado era capaz de ajustar } \\
\text { la estructura del texto explicativo a las características del } \\
\text { receptor. }\end{array}$ \\
\hline $\begin{array}{l}\text { Naturaleza de la explicación } \\
\text { científica }\end{array}$ & $\begin{array}{l}\text { Actividad de } \\
\text { síntesis }\end{array}$ & $\begin{array}{l}\text { Enseñar las componentes de una argumentación y construir } \\
\text { una «base de orientación». }\end{array}$ \\
\hline $\begin{array}{l}\text { Enfermedad genética de un } \\
\text { bebé por nacer }\end{array}$ & $\begin{array}{l}\text { Actividad de } \\
\text { evolución de los } \\
\text { modelos }\end{array}$ & $\begin{array}{l}\text { Identificar si el estudiantado activaba un modelo complejo de } \\
\text { salud. Reconocer la utilización de la base de orientación para } \\
\text { regular y orientar las explicaciones. }\end{array}$ \\
\hline \multicolumn{3}{|c|}{ Narrativa «Porfiria eritropoyética congénita» } \\
\hline $\begin{array}{l}\text { Retextualización: Explicación a } \\
\text { una anciana de los Cárpatos }\end{array}$ & $\begin{array}{l}\text { Actividad de } \\
\text { aplicación }\end{array}$ & $\begin{array}{l}\text { Identificar si las y los estudiantes ajustaban sus explicaciones en función } \\
\text { de la base de orientación elaborada y atendiendo a las particularidades } \\
\text { que pudiera exbibir el receptor. }\end{array}$ \\
\hline \multicolumn{3}{|c|}{ Coevaluación de los textos producidos («conversación evaluativa») } \\
\hline Guión radial de la OMS & $\begin{array}{l}\text { Actividad de } \\
\text { aplicación }\end{array}$ & $\begin{array}{l}\text { Relevar si el estudiantado identificaba diferentes formatos de } \\
\text { explicación de acuerdo con la base de orientación. }\end{array}$ \\
\hline Actividad de coevaluación & $\begin{array}{l}\text { Actividad de } \\
\text { evaluación }\end{array}$ & $\begin{array}{l}\text { Relevar si el estudiantado era capaz de identificar la calidad de } \\
\text { las producciones de sus compañeros en función de criterios } \\
\text { discutidos previamente. } \\
\text { Relevar el despliegue de estrategias metacognitivas. }\end{array}$ \\
\hline \multicolumn{3}{|c|}{ Narrativa «Encefalitis por virus Nipah» } \\
\hline Elaboración de listados & $\begin{array}{l}\text { Actividad de } \\
\text { evolución de los } \\
\text { modelos }\end{array}$ & $\begin{array}{l}\text { Relevar si el estudiantado identificaba los aspectos } \\
\text { multirreferenciales y multicausales en la narrativa presentada. }\end{array}$ \\
\hline Congreso de virología & $\begin{array}{l}\text { Actividad de } \\
\text { aplicación }\end{array}$ & $\begin{array}{l}\text { Identificar si el estudiantado era capaz de ajustar la explicación } \\
\text { en función del formato y el receptor. } \\
\text { Reconocer si el estudiantado activaba el modelo multicausal y } \\
\text { multirreferencial. }\end{array}$ \\
\hline Actividad de autoevaluación & $\begin{array}{l}\text { Actividad de } \\
\text { evaluación }\end{array}$ & $\begin{array}{l}\text { Identificar en qué medida el estudiantado reflexionaba acerca } \\
\text { de su desempeño en la elaboración de una explicación. } \\
\text { Relevar el despliegue de estrategias metacognitivas. }\end{array}$ \\
\hline Postest: Examen trimestral & $\begin{array}{l}\text { Actividad de } \\
\text { evaluación }\end{array}$ & $\begin{array}{l}\text { Identificar la calidad del texto explicativo elaborado y la } \\
\text { activación del modelo complejo de salud-enfermedad para el } \\
\text { caso del origen del VIH. }\end{array}$ \\
\hline
\end{tabular}

Ahora bien, como ya se indica en la Tabla 1, el presente trabajo se enfoca en una pequeña sección de la secuencia didáctica; tal sección está organizada, tanto en su diseño como en su implementación, en torno a la enseñanza explícita de las componentes, sus respectivas variables y sus indicadores (tomados de Adúriz-Bravo 2012: 66). Las componentes enseñadas 
se constituyen, a través de una operacionalización de sus variables y subvariables (Tabla 2), en las categorías de análisis de las producciones argumentativas del estudiantado.

Tabla 2. Componentes argumentativas, variables y subvariables para el análisis (tomado de Revel Chion 2012: 126).

\begin{tabular}{|c|c|c|}
\hline Componentes & Variables & Subvariables \\
\hline \multirow[t]{3}{*}{ Componente retórica } & Apela a la autoridad científica & \\
\hline & Opone a lo que el receptor sabe & \\
\hline & $\begin{array}{l}\text { Alerta acerca de la importancia del cambio } \\
\text { epistémico }\end{array}$ & \\
\hline \multirow{4}{*}{$\begin{array}{l}\text { Componente } \\
\text { pragmática }\end{array}$} & \multirow[t]{2}{*}{ Reconoce el contexto de la explicación } & Texto coloquial o formal \\
\hline & & Usa $2^{\mathrm{a}}$ o $3^{\mathrm{a}}$ persona \\
\hline & \multirow[t]{2}{*}{ Tiene en cuenta el nivel educativo del receptor } & Paráfrasis, metáforas \\
\hline & & $\begin{array}{l}\text { Toma en cuenta conocimientos de } \\
\text { partida }\end{array}$ \\
\hline \multirow[t]{4}{*}{ Componente teórica } & Concepciones de salud y ambiente & \\
\hline & Conocimiento de la enfermedad & \\
\hline & Vocabulario técnico adecuado & \\
\hline & Establecimiento de inferencias & \\
\hline \multirow[t]{5}{*}{ Componente lógica } & Presencia de conectores & \\
\hline & \multirow[t]{2}{*}{ Macroestructura y superestructura } & Coherencia global \\
\hline & & Discurso ordenado \\
\hline & \multirow[t]{2}{*}{ Conclusiones } & Coherencia con datos \\
\hline & & Uso de conector especifico \\
\hline
\end{tabular}

Este trabajo es un extracto de un estudio cualitativo exploratorio con diseño clásico pre-post. Presenta el análisis que hacemos de las producciones de un grupo de 5 estudiantes (intencionalmente seleccionados del total de 51 participantes de acuerdo con su nivel de rendimiento general) en una actividad de aplicación. La actividad («Explicación a una anciana de los Cárpatos») demandó la retextualización de una narrativa sobre vampiros y porfiria que la antecedía en la secuencia didáctica.

\section{Descripción de la actividad «Explicación a una anciana de los Cárpatos»}

Según Méheut y Psillos (2007), las secuencias didácticas (o «de enseñanza-aprendizaje») están relacionadas con la metodología de la investigación-acción, en la que operan simultáneamente como abordaje de aula innovador y como herramienta de investigación didáctica. Una secuencia didáctica es, desde esta perspectiva, a la vez una actividad de investigación intervencional y evaluativa y un producto educacional que incluye actividades de enseñanza que devienen en insumos para la investigación.

La temática de salud abordada en la actividad bajo estudio se vincula con las enfermedades de tipo genético, y examina una muy particular, de baja incidencia: la «porfiria eritropoyética congénita», o mal de Günther. Esta es una enfermedad autosómica recesiva ligada al par 18; el gen dañado genera disfunción en una enzima, lo que conduce a la acumulación de porfirinas. En esta rara condición médica los pacientes exponen atributos como actinismo (la luz solar les provoca lesiones en la piel, enrojecimiento, dolor, sensación de calor, ampollas y grietas sangrantes), hipertricosis (crecimiento excesivo de pelo en lugares poco comunes), destrucción prematura de los glóbulos rojos (lo que causa anemia y hemorragias) y eritrodoncia (coloración rojiza de los dientes por acumulación de porfirinas en el esmalte).

Según algunas hipótesis médicas, todos estos síntomas parecen haber contribuido a constituir la imagen mitopoética del vampiro (Revel Chion et al. 2004): un espectro diabólico nocturno que se alimenta de sangre humana. Los vampiros suelen ser descritos con grandes colmillos, 
uñas largas y palidez notable; se dice que no pueden resistir la luz del día y que no soportan oler el ajo.

Para el abordaje en clase de las características del mal de Günther y de su uso para «explicar»el vampirismo, se usó una narrativa elaborada a partir de la lectura de varias fuentes académicas (Elder 1972; Cereijido 1997; Rossetti et al. 2007). Al construirla tuvimos en cuenta la inclusión de las diferentes «causas» que pueden haberse conjugado en la prevalencia de la enfermedad en los tiempos y lugares de las leyendas vampíricas, para lo cual adquirió centralidad la explicitación de la influencia del ambiente, considerado en sentido amplio (Revel Chion 2015). De esta manera se pretendía que el estudiantado identificara los factores biológicos, sociales, históricos, económicos y políticos involucrados.

Describimos a continuación la actividad desarrollada por el estudiantado y las intervenciones anteriores de la docente-investigadora. Se destinaron varios encuentros a la enseñanza de la naturaleza de la competencia argumentativa, durante los cuales se instó al estudiantado a reflexionar acerca de qué características debía exponer un texto que persiguiera explicar un hecho a alguien. La profesora fue introduciendo preguntas que daban cuenta de las cuatro componentes, tales como: con qué recursos del lenguaje se podría lograr un texto accesible a individuos con escasos conocimientos de biología, qué ajustes se podrían hacer conservando la solidez de la teoría, qué modificaciones deberían hacerse si el contexto de emisión del texto fuera informal, etc. En esta instancia de la secuencia se llega a acuerdos acerca de todos esos aspectos; tales acuerdos no son preexistentes, sino construidos conjuntamente por los interlocutores en el acto mismo de la comunicación interactiva. Se dice entonces que el significado «se negocia» para destacar el papel que cumplen todos los interlocutores en la cocreación (Alemany 2000).

Con el objetivo de que los estudiantes adquirieran progresivamente mayor autonomía en la producción de argumentaciones, se co-construyó la base de orientación, que contempló las cuatro componentes y se convirtió en el dispositivo consensuado para guiar la producción y evaluación de las producciones. Al mismo tiempo que se trabajaba sobre la competencia argumentativa, la profesora introducía el modelo teórico multicausal/multirreferencial de enfermedad y presentaba el mal de Günther mediante una narrativa (oral y luego entregada también por escrito).

La consigna que recibió el estudiantado fue la de «retextualizar» la narrativa de vampiros y porfiria, ahora bajo la forma de una «explicación científica» con destinatario y contexto bien determinados. Las y los estudiantes debían reconocerse en la situación de estar realizando una visita a los montes Cárpatos, durante la cual encontraban a una anciana valaca o transilvana influenciada por las antiguas leyendas, que exigía argumentos en torno a por qué sus vecinos aparentemente eran vampiros:

Estando de vacaciones en la zona de los Cárpatos y dando un paseo por una pequeña aldea, conocés a una viejita con la que entablás una conversación. La viejita, atada a antiguos prejuicios y tradiciones, te comenta que no logra comprender cómo es que tantos de sus vecinos son «vampiros». Escribi la explicación que le darías.

Con contexto y receptora tan claramente identificados para la argumentación, las y los estudiantes debían determinar con qué saberes cuenta la anciana rumana, qué ideas míticas de ella son las que deberían ser reemplazadas por nociones científicas y cuál tendría que ser el objetivo epistémico principal que se persigue con la explicación que aportarían (Cassany 2012).

Una vez elaborados los textos, la profesora propuso que se los coevaluara. Las y los estudiantes analizan sus producciones con el auxilio de la profesora y la guía de los criterios previamente negociados: adecuar la explicación a la destinataria, utilizar los argumentos de 
manera tal de convencerla, identificar las ideas teóricas fundamentales para la explicación, dar al texto una estructura robusta (no «telegráfica»), usar apropiadamente conectores y establecer una conclusión bien indicada. Tales criterios tenían 4 valores asignables: 1 . no lo supo hacer; 2. supo hacerlo hasta cierto punto, pero todavía tiene dificultades; 3. lo supo hacer bien; y 4. supo hacerlo muy bien y podría explicarle a un compañero o compañera cómo hacerlo. En plenario, el estudiantado puntuaba el logro de cada criterio en las producciones y hacía sugerencias de mejora en los casos en los que la valoración fuera de 1 o 2.

En esa instancia de revisión colectiva se retroalimenta cada producción individual según la sugerencia de Richard Duschl (1998: 11) de que «tanto los criterios para la evaluación de los productos y actuaciones de los estudiantes como los productos y actuaciones mismas, se comparten públicamente, empleando una estrategia directa de enseñanza denominada "conversación de evaluación"». Después de la conversación de evaluación se pidió a las y los participantes la reelaboración individual de sus textos atendiendo a las sugerencias y la entrega de nuevas versiones «ajustadas», que son las que se analizan aquí.

El análisis de la producción del estudiantado en esta actividad en particular, pero hecho a la luz de las demás producciones anteriores recogidas, nos permite construir «evidencias» del ajuste progresivo de sus explicaciones a la noción de argumentación sostenida en clase, con particular foco en el uso del modelo teórico. En este sentido, nos enfocamos en la capacidad de las y los adolescentes participantes para utilizar con solvencia las categorías de la Tabla 2 (es decir, para «seguir de cerca» la base de orientación) y para adecuar sus argumentos a los requerimientos introducidos por la consigna sin desvirtuar lo «irreducible» del contenido disciplinar. Nuestro análisis permitiría también inferir algunos signos del uso de estrategias autorregulatorias.

\section{Resultados y discusión}

Exponemos aquí el análisis del texto de explicación sobre vampiros y porfiria en su versión final corregida tras la coevaluación para el caso de 5 estudiantes (extraídos de entre los 51 participantes de la investigación) con rendimiento general bien diferenciado en función de las calificaciones obtenidas en evaluaciones formales de corte y en el trabajo en clase. En el contrato didáctico establecido con el estudiantado se acordó la existencia de tareas semanales cuyos resultados acumulados constituirían una calificación trimestral que denominamos «trabajo en clase». Tal calificación -por decisión de la institución escolar- se promedia con otras obtenidas de evaluaciones escritas y demás trabajos; por tanto, las y los estudiantes asumen la importancia otorgada a la resolución de las tareas domiciliarias.

Se eligieron dos estudiantes de muy buen rendimiento (A y B), dos de rendimiento intermedio (C y D), y uno de rendimiento regular-bajo (E). En líneas generales, los estudiantes de buen rendimiento resuelven satisfactoriamente todas las tareas y cumplen con lo establecido; son ordenados y regulan eficientemente los momentos de distracción y retorno a la actividad. Aquellos identificados como de rendimiento intermedio se caracterizan por la disparidad en la calidad de sus producciones; en muchas ocasiones el sostenimiento de la atención en el trabajo oscila. Finalmente, el estudiante de rendimiento bajo muestra deficiencias en las producciones por la combinación de algunos de estos motivos: errores de comprensión de las consignas, defectuosa apropiación de los modelos teóricos, distracciones, incumplimiento de las tareas.

En nuestro análisis procuramos reconocer en los textos de esos 5 estudiantes las cuatro componentes argumentativas, para luego enmarcar algunos elementos textuales en las categorías y variables de la Tabla 2 sin descartar información. Se exponen a continuación extractos de esos textos para mostrar instanciaciones de las categorías teóricas en la producción del estudiantado para esta tarea. 


\section{Componente retórica}

En esta categoría delimitamos tres variables: apelar a la autoridad científica, oponer lo emitido a los saberes del receptor, y alertar al receptor acerca de la conveniencia de un cambio en su conocimiento. La Tabla 3 presenta extractos codificados de las producciones del estudiantado.

Tabla 3. Componente retórica en las producciones del estudiantado.

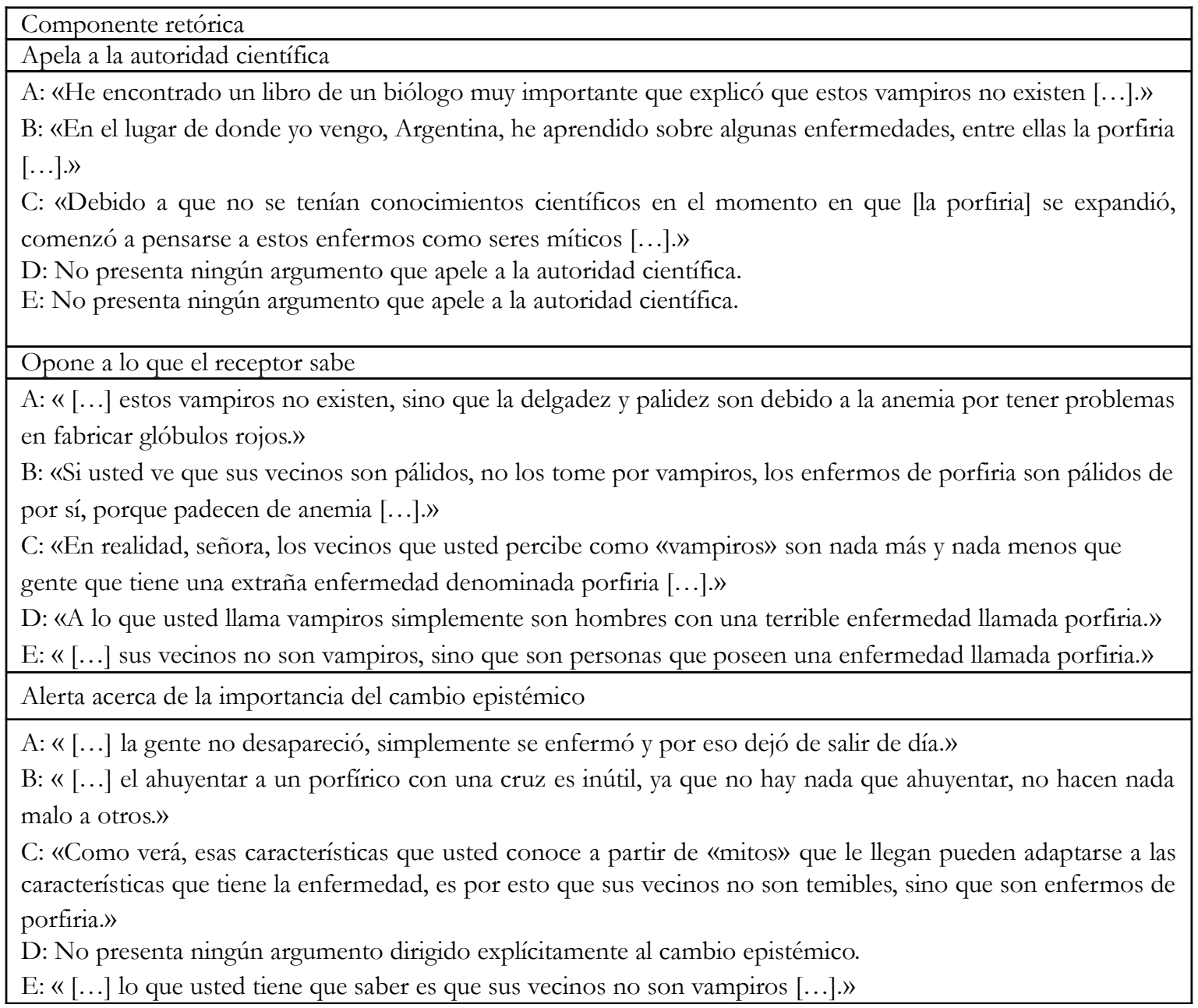

En líneas generales, para esta componente, las y los estudiantes exponen explicaciones satisfactoriamente ajustadas a la estructura de argumentación consensuada en clase, es decir, muestran tener presente la base de orientación. Todos logran oponer el saber «modeloteórico» a lo que la ancianita ya sabe (y en este sentido llama la atención que las formulaciones son muy similares en los estudiantes B a E). Se podría entonces asumir que, en lo que atañe a trabajar con la retórica de la argumentación, la elección de la interlocutora fue acertada, en el sentido de que hizo posible un distanciamiento significativo del contexto normativo de aula, lo que estimuló y facilitó la tarea de intentar convencer.

Por otra parte, la temática de la narrativa presentada parece haber resultado motivadora: el mito de los vampiros, utilizado como recurso para introducir la porfiria, parece haber actuado como un incentivo potente para las y los estudiantes, por lo menos los de mayor rendimiento, en los cuales se ven mecanismos textuales dirigidos a provocar el cambio epistémico en la destinataria («sus vecinos no son temibles», «no hacen nada malo»). En el caso de la estudiante $\mathrm{D}$, la componente retórica aparece concentrada únicamente en la oposición entre el saber médico y el mitopoético. 


\section{Componente pragmática}

Las y los estudiantes seleccionados elaboran explicaciones en lenguaje coloquial, recurren a la segunda persona del singular para dirigirse a su interlocutora y utilizan paráfrasis o metáforas medianamente adecuadas al perfil de la destinaria. Se muestran en la Tabla 4 ejemplos de estas variables.

Tabla 4. Componente pragmática en las producciones del estudiantado.

\begin{tabular}{|l|}
\hline Componente pragmática \\
\hline Contexto de la explicación: Texto coloquial y uso de la $2^{\text {a }}$ persona \\
\hline A: «Quisiera tener el honor de hablar con usted sobre los vampiros, si es que acaso está dispuesta, me gustaría \\
que me contara acerca de esta historia.» \\
B: «Si usted ve que sus vecinos son pálidos, no los tome por vampiros [...].» \\
C: «Como verá, esas características que usted conoce a partir de “mitos» que le llegan [...].» \\
D: «A lo que usted llama vampiros simplemente son hombres con una terrible enfermedad [...].» \\
E: «Señora, lo que usted tiene que saber es que sus vecinos no son vampiros [...].» \\
\hline Nivel educativo del receptor: Saberes de partida y paráfrasis y metáforas \\
\hline A: «Los enfermos de porfiria son delgados y pálidos, esto es porque están anémicos y tienen una carencia de \\
glóbulos rojos, por eso es que se ven blancos y demacrados.» \\
B: «Si usted ve que sus vecinos son pálidos, no los tome por vampiros, los enfermos de porfiria son pálidos de \\
por sí, porque padecen de anemia, pero además una falla en su composición física hace que no soporten el sol \\
{$[\ldots .] . »$.} \\
C: «Son nada más y nada menos que gente que tiene una extraña enfermedad denominada porfiria, la cual se \\
traspasa de generación en generación, es decir, en la familia.» \\
D: No presenta ningún argumento en el que se adecue el lenguaje técnico a los conocimientos de la receptora. \\
E: « [...] esta enfermedad provoca anemia, es decir, la sangre tiene menos glóbulos rojos de lo normal.» \\
\hline
\end{tabular}

La adecuación del lenguaje al contexto de emisión y a las características de la destinataria es satisfactoria. En este sentido, sobresale la paráfrasis que el estudiante $\mathrm{C}$ hace de «enfermedad genética» como «que se traspasa de generación en generación, es decir, en la familia». No obstante ello, persiste un lenguaje medicalizado y las paráfrasis y metáforas quedan a veces con poco alcance. Al mismo tiempo, los saberes de la receptora son tenidos en cuenta solo parcialmente («no los tome por vampiros», «conoce a partir de mitos que le llegan»).

Tal como se señaló en el análisis de la componente anterior, nuevamente parece que la consigna habilita al estudiantado a desligarse, aunque más no sea parcialmente, de la clásica explicación formal requerida en la ciencia escolar. En este sentido, es interesante el modo en que recurren a ingeniosas estructuras con el fin de captar la atención de la destinataria: «Quisiera tener el honor de hablar con usted sobre los vampiros, si es que acaso está dispuesta, me gustaría que me contara acerca de esta historia».

\section{Componente teórica}

Las evidencias apuntan a que las y los estudiantes asumen una concepción de la salud en relación con el ambiente cercana a la previamente discutida en clase, que sostienen a lo largo de la actividad. Al momento de esta tarea, los participantes ya habían atravesado instancias de enseñanza y lecturas de textos en relación con esa relación, razón por la cual estos resultados serían los deseables. Se observa en la Tabla 5 un dominio aceptable del conocimiento teórico acerca de la enfermedad, que no fue obstruido por la complejidad de la tarea argumentativa. Así, las condiciones impuestas por la consigna permitieron a las y los adolescentes poner en evidencia su conocimiento de la porfiria, lo que ajusta a la idea de Kuhn (1993) de que esta tarea argumentativa funciona como «ventana» al conocimiento del estudiantado. 
Tabla 5. Componente teórica en las producciones del estudiantado.

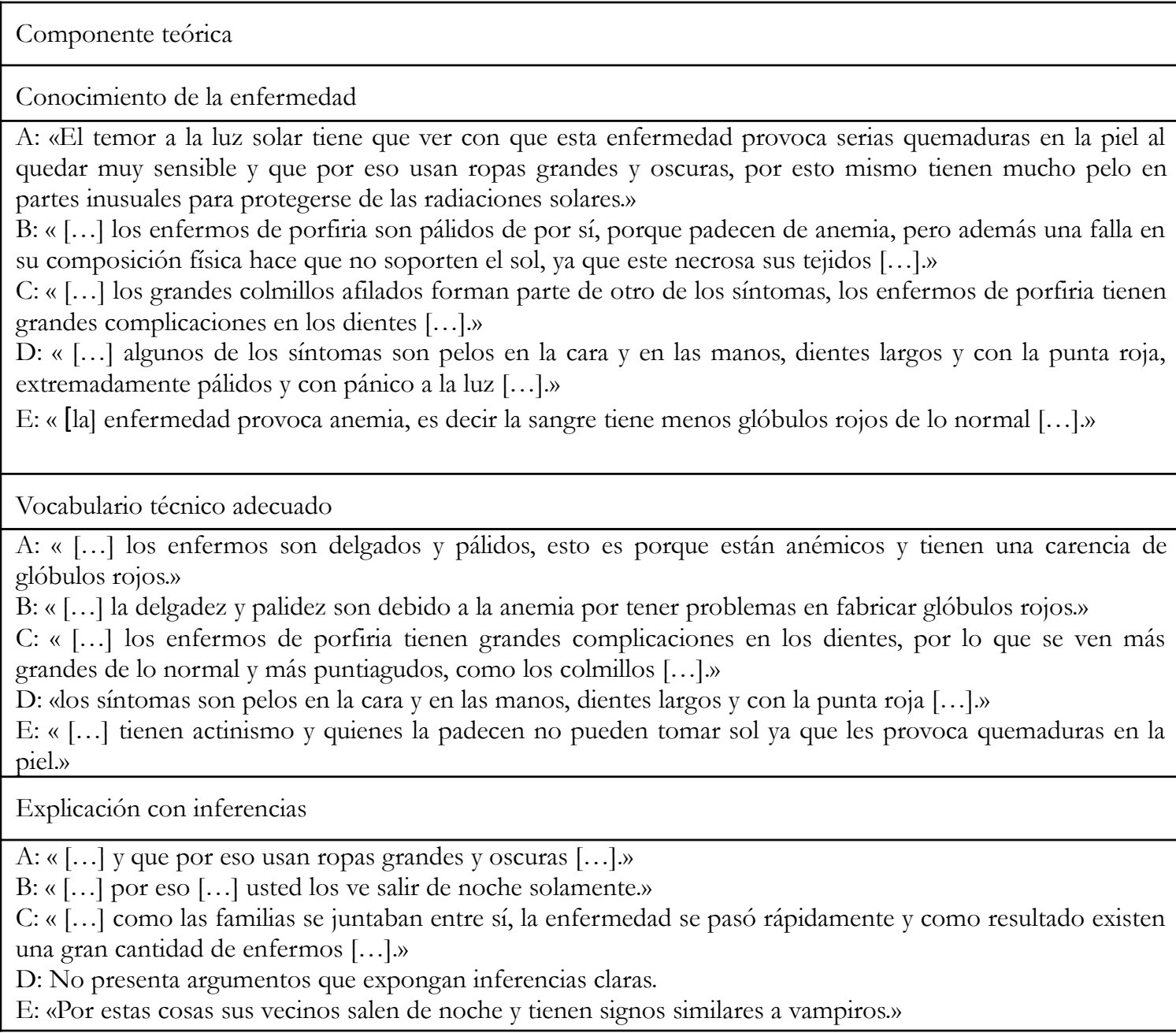

En relación con la variable del uso adecuado del vocabulario técnico, las y los estudiantes a veces parecen perder de vista que su administración debe depender estrechamente de las características del receptor; recurren a términos tales como «glóbulos rojos», «anemia» o «actinismo», que parecen poco amigables para con la ancianita de los Cárpatos. Probablemente este desacierto se vincule con la creencia de que el ajuste a la jerga científica es lo que se espera de ellos en el contexto escolar y da la necesaria «solidez» a sus explicaciones.

En lo que se refiere a la inclusión de inferencias en la explicación, 3 estudiantes dan razones para los ropajes y hábitos nocturnos de los vampiros, pero en general aparece poco desarrollada la cadena de causas y consecuencias (incluso se observa que el texto de la estudiante D no expresa ninguna inferencia clara). En suma, el cuidado que el estudiantado pone en la componente teórica de sus argumentos puede llevar a una interferencia parcial con las componentes pragmática y retórica, que quedarían supeditadas a la primera en los trechos más «duros» del discurso médico.

\section{Componente lógica}

Esta categoría atiende a la coherencia global del texto en términos de tres variables: estructura, conectores y conclusión. La estructura de los textos es muy satisfactoria, como se discutirá en el próximo apartado; sin embargo, en algunos casos, las y los estudiantes, en el afán de que su interlocutora comprendiera una explicación que hiciera posible superar su concepción mitopoética de los vampiros, han «sobrecargado» el texto. Han yuxtapuesto partes y han 
vuelto sobre sus pasos reiterando algunos aspectos en las explicaciones, lo que hace perder parcialmente la ilación.

Los extractos en la Tabla 6 dan cuenta de que el estudiantado realiza una aceptable utilización de los conectores, aunque ellos son poco elaborados. Finalmente, respecto de la inclusión de conclusiones, se han evidenciado buenos desempeños: las y los estudiantes cierran adecuadamente sus textos usando conectores indicativos («como resultado», «en conclusión»).

Tabla 6. Componente lógica en las producciones de los estudiantes.

\begin{tabular}{|l|}
\hline Componente lógica \\
\hline Presencia de conectores \\
\hline A: « $[\ldots]$ por esto mismo tienen mucho pelo $[\ldots] . »$ \\
B: « $[\ldots]$ ya que este necrosa sus tejidos $[\ldots] . »$ \\
C: «El hecho de que «vivan de noche» como suele decirse no es para planear maldades, sino porque la luz de sol les \\
produce fuertes quemaduras $[\ldots] . »$ \\
D: « $[\ldots]$ síntomas como pelos en la cara $[\ldots]$ entre otros.» \\
E: « $[\ldots]$ poseen pánico al sol, ya que tienen actinismo y quienes [padecen la enfermedad] no pueden tomar \\
sol, ya que les provoca quemaduras en la piel.» \\
\hline Conclusiones \\
\hline A: «En conclusión, la gente no desapareció, simplemente se enfermó y por eso dejó de salir de día.» \\
B: «De este modo, el ahuyentar a un porfírico con una cruz es inútil $[\ldots] »$ \\
C: « $[\ldots]$ y como resultado, existen una gran cantidad de enfermos a su alrededor, pero le aseguro que no tiene \\
que temer.» \\
D: No establece una conclusión. \\
E: «Por estas cosas sus vecinos salen de noche y tienen signos similares a vampiros.» \\
\hline
\end{tabular}

\section{Balance entre componentes: ejemplos de análisis global}

Mostramos aquí los tres textos completos correspondientes a un estudiante de cada grupo de rendimiento, para que los lectores tengan una vista de su coherencia de conjunto (macro- y superestructura) y de las relaciones que se establecen entre las cuatro componentes (que aquí señalamos como R[etórica], P[ragmática], T[eórica] y L[ógica]).

En cuanto a la variable de coherencia global de la componente lógica, se identifica que el estudiantado elabora argumentaciones adecuadamente cohesionadas, lo que puede ser «herencia» de su práctica en explicaciones más formales dirigidas a la profesora. El balance entre componentes, en cambio, es más diverso entre estudiantes.

Texto del estudiante A, de rendimiento alto:

«-Quisiera tener el honor de hablar con usted sobre los vampiros, si es que acaso está dispuesta, me gustaría que me contara acerca de esta historia $[\mathrm{R}, \mathrm{P}] \ldots$

-Sí, cómo no... hasta donde yo sé... hace muchos años existieron en esta aldea muchos vampiros que salían por la noche a devorar la sangre de las personas, por lo que están siempre jóvenes.

-¿Y cómo es su aspecto?

-Son pálidos con dientes afilados y rojizos, abundante vello facial, salen de noche porque el sol es su peor enemigo y el ajo les hace mal tanto como una cruz.

-Sobre esto quisiera detenerme $[\mathrm{R}]$... He encontrado un libro de un biólogo muy importante que explicó que estos vampiros no existen $[R, T]$, sino que la delgadez y palidez son debido a la anemia, por tener problemas en fabricar glóbulos rojos [P, T]. El temor a la luz solar tiene que ver con que esta enfermedad provoca serias quemaduras 
en la piel al quedar muy sensible [T, P] y que por eso [L] usan ropas grandes y oscuras, por esto mismo tienen mucho pelo en partes inusuales para protegerse de las radiaciones solares $[\mathrm{T}, \mathrm{L}]$.

- ¿Y por qué ha desaparecido gente de ellos en el día? -preguntó la anciana.

-En conclusión, la gente no desapareció, simplemente se enfermó y por eso dejó de salir de día $[\mathrm{L}, \mathrm{R}] . »$

El estudiante elabora un texto en forma de diálogo, que es coherente y bien hilado. A lo largo de él, tiene muy en cuenta el contexto de emisión, apela a la autoridad científica, opone el modelo teórico a lo que la receptora sabe, glosa parcialmente las ideas más difíciles. Muestra conocimiento adecuado sobre la porfiria e intenta aligerar el vocabulario técnico y explicitar causas y consecuencias. Establece explícitamente una conclusión que además apunta a cambiar el estatus epistémico del viejo y nuevo saber en la anciana.

Texto de la estudiante $\mathrm{C}$, de rendimiento medio:

«En realidad, señora, los vecinos que usted percibe como "vampiros" son nada más y nada menos que gente que tiene una extraña enfermedad denominada porfiria $[R]$, la cual se traspasa de generación en generación, es decir, en la familia $[\mathrm{P}, \mathrm{T}]$. Debido a que no se tenían conocimientos científicos en el momento en que esta se expandió, comenzó a pensarse a estos enfermos como seres míticos, es decir, vampiros [R, P, L]. Las características que usted observa y que la llevan a pensar que sus vecinos son vampiros no son nada más que síntomas que presenta la porfiria [R, T]. Como los padecientes poseen fallas al reponer su sangre, se los observa muy delgados y pálidos. El hecho de que "vivan de noche" como suele decirse no es para planear maldades, sino porque la luz de sol les produce fuertes quemaduras y lesiones en la piel [R, P, T, L]. Como una forma de protegerse de la luz es que les crecen esos pelos en los diferentes sitios como la palma de las manos [P, T, L]. Como le habrá llamado la atención, el rechazo al ajo es otra característica de los vampiros, y tal rechazo es debido a que, si llegan a comerlo, olerlo o tocarlo, puede complicarlos debido a su enfermedad [R, P, T].

El último gran mito, los grandes colmillos afilados forman parte de otro de los síntomas, los enfermos de porfiria tienen grandes complicaciones en los dientes $[R, P$, T], por lo que se ven más grandes de lo normal y más puntiagudos, como los colmillos de los que se le ha hablado [R, P, L].

Como verá, esas características que usted conoce a partir de "mitos" que le llegan pueden adaptarse a las características que tiene la enfermedad, es por esto que sus vecinos no son temibles, sino que son enfermos de porfiria $[R, T]$.

Por otro lado, como desde un principio las familias se juntaban entre sí, la enfermedad se pasó rápidamente y como resultado, existen una gran cantidad de enfermos a su alrededor $[\mathrm{P}, \mathrm{L}]$, pero le aseguro que no tiene que temer $[\mathrm{R}] . »$

En este caso, la estudiante elabora un texto en forma de alocución a la anciana, que es muy coherente y bien hilado. Se evidencia en él un continuo y satisfactorio ajuste de las componentes retórica y pragmática dirigido a convencer a la destinataria de la potencia de la explicación que se está brindando. Aunque ese ajuste aparece poco entorpecido por el apego a los requerimientos de la componente teórica, a veces esta resulta sobredimensionada. En el caso del argumento en torno al ajo, la inferencia está poco lograda. Por otra parte, la estudiante redondea el texto buscando una reacción de su interlocutora, pero la conclusión argumentativa aparece un párrafo antes, cuando se indica que los vampiros son pacientes 
porfíricos a los que no se ha de temer. Consideramos que este texto tiene una calidad global superior a la del anterior.

Texto del estudiante E, de rendimiento bajo:

Señora, lo que usted tiene que saber es que sus vecinos no son vampiros, sino que son personas que poseen una enfermedad llamada porfiria [R, T], esta enfermedad provoca anemia, es decir, la sangre tiene menos glóbulos rojos de lo normal, esto hace que sean demasiados pálidos, también poseen pánico al sol [T, L], ya que tienen actinismo y quienes la padecen no pueden tomar sol, ya que les provoca quemaduras en la piel [T, L].

Por estas cosas sus vecinos salen de noche y tienen signos similares a vampiros [L].

El texto, muy escueto, tiene una estructura lógica poco lograda, con falta de desarrollo del argumento y conexiones inferenciales flojas. No muestra intentos claros de adecuarse al contexto y a la destinataria y queda corto en intentar convencerla o provocar cambios en su saber. Las componentes retórica y pragmática han quedado completamente desdibujadas frente a la teórica, que ha acaparado el protagonismo en la argumentación. Sin embargo, el desarrollo del modelo teórico es también muy incompleto. Por último, hay una conclusión recapituladora con poca fuerza argumentativa. Se trata de un texto en el cual el carácter de argumentación es todavía muy incipiente; así, se parece a una explicación escolar tradicional.

\section{Conclusiones}

El marco teórico asumido en nuestra investigación afirma que es posible que el estudiantado de enseñanza secundaria aprenda a argumentar en ciencias experimentales por medio de una actividad cuidadosamente diseñada, socialmente compartida y metacognitivamente vigilada. Nuestros resultados parecen ajustarse a esta idea. Al mismo tiempo, consideramos que, en secuencias didácticas como la aquí presentada, es factible que el estudiantado adquiera un dominio aceptable de la competencia argumentativa y del contenido científico en forma simultánea, en acuerdo con la perspectiva de que ambos elementos deben ser enseñados explícitamente en instancias específicas. Nosotros podemos afirmar, con base en nuestros resultados y sin pretensión alguna de generalización, que los argumentos que pedimos al estudiantado resultaron un vehículo adecuado para el despliegue del modelo teórico escolar de salud-enfermedad que los estudiantes activan.

En los cinco casos analizados hay evidencias de un manejo suficiente del modelo teórico escolar de referencia sobre la porfiria de Günther cuando se argumenta. Así, el análisis de datos que presentamos parece indicar una contribución positiva del aprendizaje de la argumentación científica escolar al aprendizaje de un modelo complejo de salud-enfermedad. Estos resultados son coherentes con los reportados por González y colaboradores (2013) usando problemáticas ambientales y Rudsberg y colaboradores (2013) usando asuntos sociocientíficos. Queda pendiente profundizar en cómo la puesta en marcha de actividades que fomentan la competencia argumentativa contribuye a esa mayor comprensión de los contenidos científicos.

La calidad argumentativa es bastante más variada entre estudiantes, aunque, puestos los datos en contexto, se ven avances en todos los casos, con independencia del rendimiento general en la asignatura. Los estudiantes A, B y C responden adecuadamente a la actividad, dejando en claro el propósito de «encontrar» al receptor de su explicación y dando indicios de un manejo armónico de las cuatro componentes de la argumentación. Los estudiantes D y E, si bien realizan un intento de hacer llegar una explicación adecuada a la receptora propuesta, 
producen textos mucho más frágiles. Aunque la base de orientación utilizada ayuda a mejorar los argumentos, la tarea se muestra bien compleja.

El trabajo sostenido en torno a «hablar y escribir ciencias» es un aspecto central para aprendizajes de calidad porque permite compartir y explicitar las formas en que se interpretan los contenidos científicos escolares y al mismo tiempo contribuye al dominio de competencias de regulación del proceso de aprendizaje. Como implicación de nuestro trabajo, transformar una explicación científica teniendo en cuenta un nuevo receptor («retextualizar») supone para el estudiantado un desafío productivo: modelizar cuánto sabe un tipo de destinatario sobre el contenido acerca del que versa la explicación, cuáles son los recursos lingüísticos más adecuados para hablarle y cuáles las particularidades del contexto en que la explicación es ofrecida.

La calidad global de los textos producidos por las y los estudiantes que participaron en la implementación de nuestra propuesta didáctica también puede ser analizada críticamente en aquellos aspectos que todavía no se consiguen completamente: persiste, en algunos de los textos, pobreza en la estructura y algunas componentes se encuentran menos desarrolladas que otras. Sin embargo, en todos los casos las producciones intermedias y finales del estudiantado se muestran avanzadas respecto de las iniciales (Revel Chion 2012), lo que nos permite afirmar que el aprendizaje de los contenidos científicos y de la competencia argumentativa puede experimentar progresos importantes en tanto se aprende a argumentar, se argumenta y se reflexiona sobre la argumentación.

\section{Bibliografía}

Adúriz-Bravo A. (2008). Un modelo de ciencia para el análisis epistemológico de la didáctica de las ciencias naturales. 1er Coloquio Internacional de Didácticas y 3er Coloquio Nacional de Didáctica de las Ciencias. Ibagué, Colombia. Universidad del Tolima.

Adúriz-Bravo A. (2012). Competencias metacientíficas escolares dentro de la formación del profesorado de ciencias., pp. 43-67. En: E. Badillo, L. García, A. Marbá, M. Briceño, El desarrollo de competencias en la clase de ciencias y matemáticas Mérida: Universidad de Los Andes.

Ageitos N., Puig B., Calvo-Peña X. (2016). Trabajar genética y enfermedades en secundaria integrando la modelización y la argumentación científica. Revista Eureka sobre Enseñanza y Divulgación de las Ciencias, 14(1), 86-97. Recuperado a partir de https://revistas.uca.es/index.php/eureka/article/view/3007

Alemany I. (2000). Bases teóricas de una propuesta didáctica para favorecer la comunicación en el aula. En Jorba, J. y Prat, À. Hablary escribir para aprender. Madrid: Síntesis.

Archila P. (2013). La argumentación y sus aportes a la enseñanza bilingüe de las ciencias. Revista Eureka sobre Enseñanza y Divulgación de las Ciencias, 10(3), 406-423. Recuperado a partir de https://revistas.uca.es/index.php/eureka/article/view/2849

Archila P. (2015). Uso de conectores y vocabulario espontáneo en la argumentación escrita: Aportes a la alfabetización científica. Revista Eureka sobre Enseñanza y Divulgación de las Ciencias, 12(3), 402-418. Recuperado a partir de https://revistas.uca.es/index.php/eureka/article/view/2932

Cassany D. (2012). La cocina de la escritura. Buenos Aires: Anagrama.

Cereijido M. (1997). La muerte y sus ventajas. México: Fondo de Cultura Económica. 
Duschl R. (1997). Renovar la enseñanza de las ciencias. Importancia de las teorias y su desarrollo. Madrid: Narcea.

Duschl R. (1998). La valoración de argumentaciones y explicaciones: promover estrategias de retroalimentación. Enseñanza de las Ciencias 16(1), 3-20.

Duschl R. (2008). Quality argumentation and epistemic criteria, pp. 159-179 en S. Erduran, M.P. Jiménez Aleixandre, Argumentation in science education: Perspectives from classroom-based research. Nueva York: Springer.

Duschl R., Gitomer D. (1997). Strategies and challenges to changing the focus of assessment and instruction in science classrooms. Educational Assessment 41(1), 41-55.

Elder G. (1972). The porphyrias: A review. Journal of Clinical Pathology 25(12), 1013-1033.

González J., Sánchez L., García Á. (2013). La argumentación como vía para la mejora del aprendizaje de las ciencias: Un estudio desde las problemáticas ambientales. Enseñanz̧a de las Ciencias número extra IX Congreso Internacional, 1607-1611.

Ibacache Plaza M., Merino Rubilar C. (2021). Una propuesta de secuencia basada en el contexto, para la promoción de la argumentación científica en el aprendizaje de las reacciones químicas con estudiantes de educación media técnico profesional. Revista Eureka sobre Enseñanza y Divulgación de las Ciencias 18(1), 1105. https://doi.org/10.25267/Rev_Eureka_ensen_divulg_cienc.2021.v18.11.1105

Izquierdo M., Adúriz-Bravo A. (2003). Epistemological foundations of school science. Revista Science \& Education. 12 (1), 27-43.

Izquierdo M., Espinet M., García M.P., Pujol R., Sanmartí N. (1999). Caracterización y fundamentación de la ciencia escolar. Revista Enseñanza de las ciencias Número extra, 7992.

Jiménez-Aleixandre M.P. (2010). 10 ideas clave, Competencias en argumentación y uso de pruebas, Barcelona: Graó.

Kuhn D. (1993). Science as argument: Implications for teaching and learning scientific thinking. Science Education, 77(3), 319-337.

Leitão S. (2007). La dimensión epistémica de la argumentación. En Kronmüller E., Cornejo C. Ciencias de la Mente: Aproximaciones desde Latinoamérica. Chile: J.C. Sáez.

Maguregi Gomzález G., Uskola Ibarluzea A., Burgoa Etxaburu B. (2017). Modelización, argumentación y transferencia de conocimiento sobre el sistema inmunológico a partir de una controversia sobre vacunación en futuros docentes. Enseñanza de las Ciencias, 35(2), 29-50. Recuperado a partir de https://doi.org/10.5565/rev/ensciencias.2237

Méheut M., Psillos D. (2007). Teaching-learning sequences: aims and tools for science education research. International Journal of Science Education 26 (5), 515-535.

Osborne J., Patterson A. (2011). Scientific argument and explanation: A Necessary Distinction? Revista Science Education, 95 (4), 627-638.

Özdem Y., Cakiroglu J., Ertepinar H., Erduran S. (2017). The pedagogy of argumentation in science education: Science teachers' instructional practices. International Journal of Science Education, 39(11), 1443-1464. Recuperado a partir de: https://doi.org/10.1080/09500693.2017.1336807

Perelman C., Olbrecht-Tyteca L. (1970). La nouvelle rhétorique: Traité de l'argumentation, Université libre de Bruxelles, Bruselas. 
Perelman C. (1979). The new rhetoric: A theory of practical reasoning, pp. 140. En The new rhetoric and the humanities. Synthese Library (Studies in Epistemology, Logic, Methodology, and Philosophy of Science), Springer, Dordrecht. Recuperado a partir de: https://doi.org/10.1007/978-94-009-9482-9_1

Plantin C. (2012). La argumentación: Historia, teorias, perspectivas. Buenos Aires: Biblos.

Rescher N. (1976). Plausible reasoning: An introduction to the theory and practice of plausible inference. Aspen: Van Gorcum.

Revel Chion A., Erduran S., Adúriz-Bravo A. (2004). Argumentación científica escolar: Consensuando su significado en clases de ciencias naturales de secundaria. III Congreso Iberoamericano de Educación en Ciencias Experimentales. Desafíos y expectativas de la educación en ciencias experimentales en el siglo XXI, Resumen de ponencias, CD-ROM, $\mathrm{n}^{\circ} 63$. Guatemala: Universidad de San Carlos.

Revel Chion A. (2012). La argumentación científica escolar y su contribución para el aprendizaje de un modelo complejo de salud y enfermedad. Tesis doctoral.

Revel Chion A., Adúriz-Bravo, A. (2014). La argumentación científica escolar: Contribuciones a una alfabetización de calidad. Revista Pensamiento Americano, 7 (13), 113-122.

Revel Chion A. (2015). Educación para la salud. Enfoques integrados entre salud humana y ambiente. Propuestas para el aula. Buenos Aires: Paidós.

Rossetti M., Parera V., Melito V., Batlle A. (2007). Porfiria congénita eritropoyética en la Argentina: 4 niños y un caso de manifestación tardía. Acta Bioquímica Clínica Latinoamericana 41(3), 359-360.

Rudsberg K., Öhman J., Östman L. (2013). Analyzing students' learning in classroom discussions about socio-scientific issues. Science Education 97(4), 594-620.

Sanmartí N. (2005). La unidad didáctica en el paradigma constructivista., pp. 13-58 En: D. Couso, E. Badillo, G. Perafán y A. Adúriz-Bravo, Unidades didácticas en ciencias y matemáticas. Bogotá: Cooperativa Editorial Magisterio.

Toulmin S. (1958). The Layout of arguments, pp. 87-134 En: The uses of argument (updated ed.), Cambridge, UK: Cambridge University Press.

Van Eemeren F.H., Grootendorst R., Snoeck-Henkemans A.F. (2007). Argumentative indicators in discourse: A pragma-dialectical study. New York: Springer.

Walton D. (1989). Informal logic: A handbook for critical argumentation. Cambridge, Cambridge University Press. 